\title{
The Impact of Substation Circuit Breaker Failure Operation on System Transient Stability and Counter Measures
}

\author{
Hui Zeng, Yu Zhu, Jinsong Liu, Gang Wang, Qiang Zhang, Tao Zhang \\ Electric grid research center \\ Research Institute of Liaoning Electric Power Co., Ltd, State Grid Corporation of China \\ Shenyang, China \\ zenghui.111@hotmail.com
}

\begin{abstract}
This paper presents the impact of substation breaker failure operation on system transient stability and the ways to enhance post-fault transient characteristics. Power System Analysis Simulation Package (PSASP) software is used to stimulate the circuit breaker failure operation in $220 \mathrm{KV}$ or $500 \mathrm{KV}$ substations. By stimulating all the possible line faults and their corresponding breaker failure conditions in Liaoning electric power grid, breakers that are most likely to cause system transient unstable are researched. Reasons of transient problems are speculated and implied, using equal area criterion. Different transient characteristics led by various fault types are compared. Also, measures that could help improve system transient stability are introduced and compared. Furthermore, a new method which is integrating Thyristor Controlled Series Compensation (TCSC) to the grid weak points is stimulated and verified. Results show that it could reduce generator angle fluctuation significantly.
\end{abstract}

Keywords-Breaker failure operation, System transient stability, Equal area criterion, Tripping time reduction, Thyristor Controlled Series Compensation (TCSC)

\section{INTRODUCTION}

In the past few decades, massive amount of substations, poles and wires have been installed in China. For instance, until the end of 2012 , the number of $500 \mathrm{kV}$ and $220 \mathrm{kV}$ substations in liaoning electric grid were 23 and $234^{[1]}$. However, lack of maintenance and human mistaken operations possibly cause circuit breakers failure operation which leads to system transient unstable problems. Reasons of breakers in $10 \mathrm{kV} 6 \mathrm{kV}$ and $220 \mathrm{kV}$ substations failing to operate are researched in ${ }^{[2-7]}$. A widespread "power swing" event between 2 regional grids is described in ${ }^{[8]}$, which was caused by breakers' failure operation after a fault on an interconnected line. Unlike other papers that only focus on causes of breaker failure, this paper deals with the negative impact of breaker failure on the system transient stability. The reasons of existing "transient unstable weak points" in the grid are discussed and summarized.

\section{The Simulation Process}

\section{A. Equal area criterion}

It is possible to research transient stability by means of equal area criterion in case where one machine is swinging with respect to an infinite bus ${ }^{[9]}$. The swing equation is:

$$
\frac{d^{2} \delta}{d t^{2}}=\frac{1}{M}(P m-P e)=\frac{P a}{M}
$$

Where $P a=$ accelerating power, $M=\frac{H}{\pi f}$ is in p.u.

Thus the condition for determining stability can be written as

$$
\int_{\delta_{0}}^{\delta} \operatorname{Pad} \delta=0
$$

Equation (2) means that the system is stable if the accelerating area $\mathrm{A} 1$ under $\mathrm{Pa}-\delta$ curve equals the decelerating area A2. Fig 1(a) and (b) are $\mathrm{Pa}-\delta$ curves when short circuits fault occurs on generator outlet lines. The difference is that Fig. 1(b) has smaller $P$ max value during the fault and $P$ max is depended on $\frac{|E \| V|}{X}$.
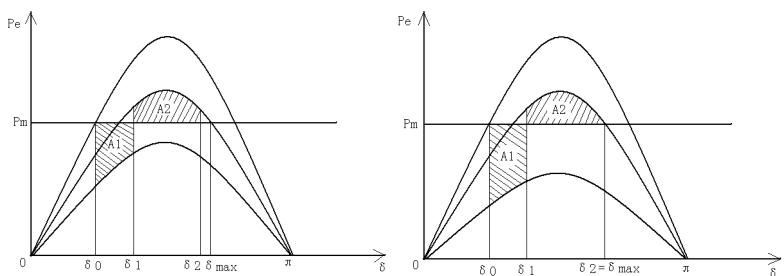

Figure 1. (a) (b) Generator $\mathrm{Pe}-\delta$ characteristics curves

Under the same pre-fault and post-fault circumstance, the generator in Fig. 1 (b) is more likely to lose synchronism because the value of $\frac{\left|E^{\prime}\right| V \mid}{X}$ is relatively smaller than that in Fig. 1(a) during the fault.

\section{B. Typical simulated regional grid framework}

Fig.2 is a typical regional grid in Liaoning electric grid, constituting one $500 \mathrm{kV}$ substation, four $220 \mathrm{kV}$ substations and one coal-fired power plant. $220 \mathrm{kV}$ substations B, C, D, $\mathrm{E}$ are interconnected between $500 \mathrm{kV}$ substation $\mathrm{A}$ and power plant F.

Fig. 3 shows the electrical circuit structure of substation D where there are 2 bus bars. Line DF and DA1 are connected to bus bar 1; line DE and DA2 are connected to bus bar 2 . 


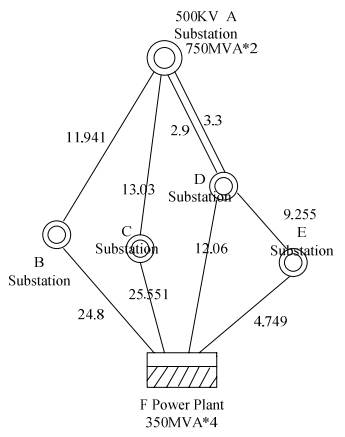

Figure 2. Local grid structure in Liaoning province

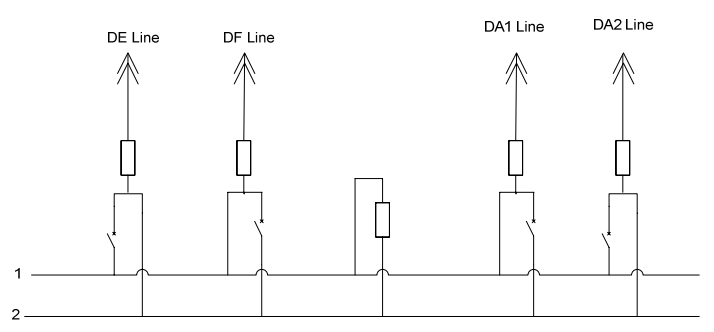

Figure 3. Electrical structure of substation D

\section{Fault point simulating setting}

To get the most serious short circuit current, adjust the regional generators' output to the upper limit. All the line faults before breaker operations are three-phase line to ground fault. Assume three-phase to ground faults on transmission lines $\mathrm{BF}, \mathrm{CF}, \mathrm{DF}$ and $\mathrm{EF}$, then breakers that are directly connected to $\mathrm{BF}, \mathrm{CF}, \mathrm{DF}$ and $\mathrm{EF}$ lines in $\mathrm{B}, \mathrm{C}, \mathrm{D}$ and $\mathrm{E}$ substations fail to operate. Circuit breakers that are near failure breakers should trip to interrupt the fault.

Note that in PSASP software, it is tacitly approved that the positions of failure circuit breakers are at $1 \%$ of line $A B$ when short circuit fault happens on point A. For instance, if the length of line $\mathrm{AB}$ is $100 \mathrm{~m}$ and a fault happens to point $\mathrm{A}$, it is a tacit recognition that the failure breaker is $1 \mathrm{~m}$ away from point $A$ and $99 \mathrm{~m}$ away from point $\mathrm{B}$.

Assume the circuit breaker operation during time is $0.12 \mathrm{~s}$ and the trip time of malfunction protection is $0.3 \mathrm{~s}$, the total operation time after fault occurs is $0.12 * 2+0.3=0.54 \mathrm{~s}$. In other words, the line fault starts at $0 \mathrm{~s}$ and breaker operation finishes at $0.54 \mathrm{~s}$.

After simulating all breaker failure conditions on the same bus bar, it is necessary to simulate breakers on the other bus bar in the same substation before the next nearby substation.

\section{Simulation results analysis}

Results show that only the fault on DF line and corresponding breaker failure in substation $\mathrm{D}$ cause generators in power plant $\mathrm{F}$ to trip (see Fig.4 and Fig.5). By contrast, all breakers' failure conditions in substation B, C and $\mathrm{E}$ have little impact on system transient stability.

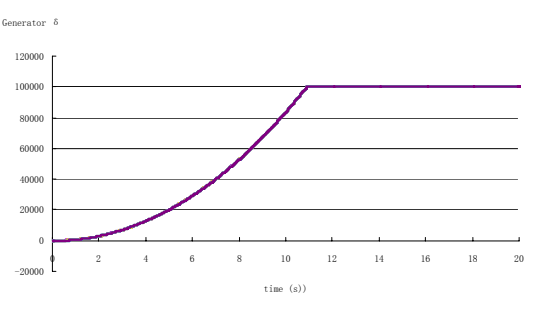

Figure 4. Pe- $\delta$ characteristics curve of Generator 1 in power plant $\mathrm{F}$

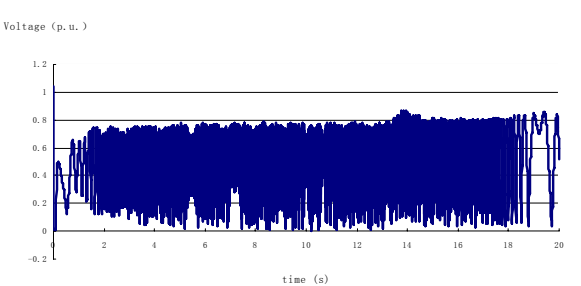

Figure 5. Voltage VS time of substation D

According to the simulation results, every substation voltage $|V|$ and generator voltage $\left|E^{\prime}\right|$ are known, thus every $|V|^{*}|E|$ are calculated (in p.u.) and compared (see Table 1).

TABLE I. CALCUlation OF POWER PLANT VOLTAGE $|V| *$ SUBSTATION VOLTAGE $\left|E^{\prime}\right|$ IN AFTER LINE FAULTS

\begin{tabular}{|c|c|c|c|}
\hline $\begin{array}{c}\text { Fault } \\
\text { line }\end{array}$ & Before fault & $\begin{array}{c}\text { During } \\
\text { fault }\end{array}$ & After fault \\
\hline DF & 1.1 & 0.001 & 0.27 \\
\hline CF & 1.1 & 0.005 & 0.47 \\
\hline EF & 1.1 & 0.0002 & 0.43 \\
\hline BF & 1.09 & 0.007 & 0.48 \\
\hline
\end{tabular}

The equivalent impedances between power plant $\mathrm{F}$ and the infinite system during line faults are calculated in table 2.

TABLE II. SYSTEM EQUIVALENT IMPEDANCE AFTER LINE FAULT

\begin{tabular}{|c|c|}
\hline Fault line & $\begin{array}{c}\text { Positive } \\
\text { impedance }\end{array}$ \\
\hline DF & 0.0215 \\
\hline CF & 0.0214 \\
\hline EF & 0.0215 \\
\hline BF & 0.0214 \\
\hline
\end{tabular}

It is also calculated that system positive impedance before and after fault is 0.0214 , thus the pre-fault, duringfault and post-fault $\frac{\left|E^{\|}\right| V \mid}{X}$ values of $\mathrm{DF}, \mathrm{CF}, \mathrm{EF}$ and $\mathrm{BF}$ lines could be calculated and shown in tables 3. Calculated value of $\frac{\left|E^{\|}\right| V \mid}{X}$ before, during and after line faults for fault lines

Therefore, Pe- $\delta$ characteristics curve of power plant $\mathrm{F}$ after fault are as follows. It is indicated that Fig. 6 (d) has the minimum deceleration area and a relatively large acceleration area, causing huge gap between $\mathrm{A} 1$ and $\mathrm{A} 2$, therefore rotor speed rises to infinity. The system can not reach a new steady state status. 
TABLE III. CAlCulated VAlue of $\frac{\left|E^{\prime}\right| V \mid}{X}$ BeFore, DURING AND AFTER LINE FAULTS

\begin{tabular}{|c|c|c|c|}
\hline Fault lines & Pre-fault & During-fault & Post-fault \\
\hline DF line & 51.3 & 0.05 & 12.33 \\
\hline CF line & 51.28 & 0.24 & 22.12 \\
\hline EF line & 51.4 & 0.01 & 19.9 \\
\hline BF line & 51.09 & 0.33 & 22.56 \\
\hline
\end{tabular}

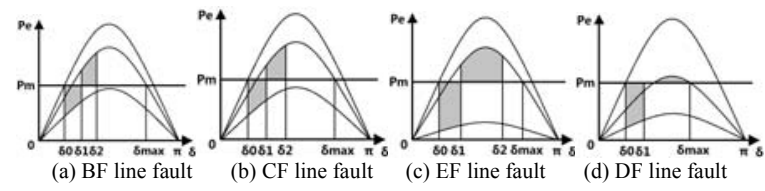

Figure 6. Pe- $\delta$ characteristics curve of power plant $F$ after fault

Additionally, other $220 \mathrm{kV}$ substations in Liaoning electric grid like D are also unstable. These substations have so much in common that they are all connected to a $500 \mathrm{kV}$ substation through double overhead lines. On the other hand, they are all directly linked to a power plant. When fault occurs and breakers fail to trip in these substations, the voltage reduction is huge and double connected lines increase the impedance of the local grid. Therefore, $\frac{|E| V \mid}{X}$ of during-fault and post-fault decreases and deceleration area shrinks so fast that it is no long equal to the acceleration area.

\section{COUNTER MEASURES TO IMPROVE POST-FAULT TRANSIENT STABILITY}

\section{A. Reducing malfunction protection time}

The most fundamental way is to decrease tripping time. Take D substation for example, reduce the malfunction protection time from $0.3 \mathrm{~s}$ to $0.29 \mathrm{~s}$ and $0.14 \mathrm{~s}$, new $\mathrm{Pe}-\delta$ characteristics curve becomes as follows. The maximum rotor angle oscillations are reduced to $200^{\circ}$ and $80^{\circ}$ respectively. It is indicated that reducing tripping time is the most effective method of improving transient stability.

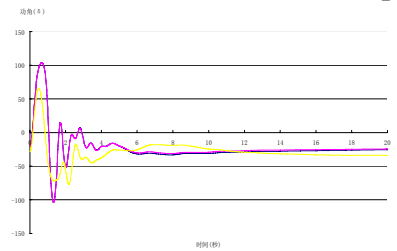

(a)

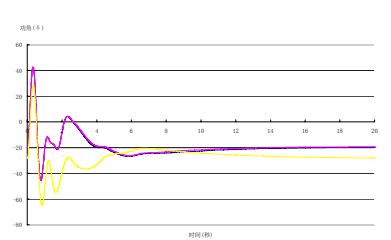

(b)
Figure 7. Malfunction protection time are decreased to $0.29 \mathrm{~s}$ and $0.14 \mathrm{~s}$ (a)(b) are $\mathrm{Pe}-\delta$ characteristics curves

\section{B. Integrating TCSC}

Another method is to integrate Thyristor controlled series compensation (TCSC) between substation D and A, using User-defined (UD) model ${ }^{[10]}$, to integrate 6094 TCSC model between substation D and A. TCSC's function which is decreasing impedance and increasing $\frac{|E \| V|}{X}$ is realized ${ }^{[11]}$. Following are the comparisons between pre-integration and post-integration of TCSC under 3-phase, 2-phase and 1phase fault and breaker failure operation conditions.

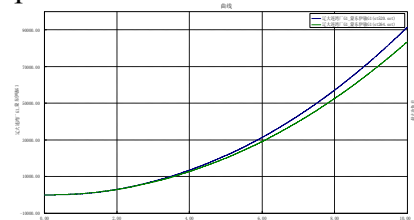

(a)

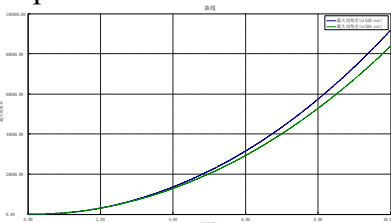

(b)
Figure 8. After the ABC 3-phase short circuit fault on line DF (a) Pe- $\delta$ characteristics of Generator 1 in power plant $\mathrm{F}$ before and after TCSC is integrated (b) The maximum angle difference before and after TCSC is integrated

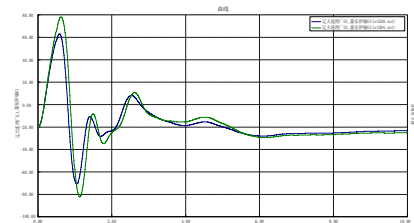

(a)

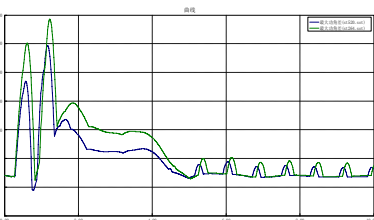

(b)
Figure 9. After the AB 2-phase short circuit fault on line DF (a) Pe- $\delta$ characteristics of Generator 1 in power plant $\mathrm{F}$ before and after TCSC is integrated (b) The maximum angle difference before and after TCSC is integrated

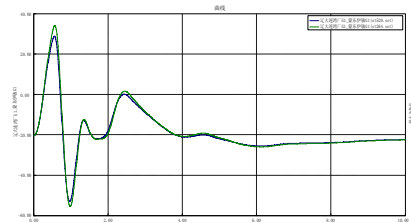

(a)

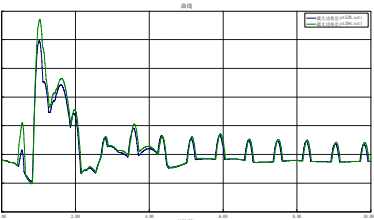

(b)
Figure 10. After the A 1-phase short circuit fault on line DF (a) Pe- $\delta$ characteristics of Generator 1 in power plant $\mathrm{F}$ before and after TCSC is integrated (b) The maximum angle difference before and after TCSC is integrated

Simulation results indicate that TCSC has no significant impact on 3-phase fault conditions and generators still loss synchronization. But in 2-phase and 1-phase fault cases, integrating TCSC slightly reduces the rotor angle maximum oscillations by $24^{\circ}$ and $7^{\circ}$. The stability tolerance of TCSC is much higher than that of non-TCSC grid network ${ }^{[12]}$. However, in this case, TCSC could only be used as an auxiliary way of reducing the impact of breaker failure on stability.

\section{CONCLUSIONS}

Circuit breaker failure operations in $220 \mathrm{KV}$ and $500 \mathrm{KV}$ substations are simulated and the results are compared. For $220 \mathrm{kV}$ substation which are both connected to a $500 \mathrm{kV}$ substation through double overhead lines and directly connected to a power plant, the impact of substation breaker failure on system transient stability is obvious.

Several anti transient un-stability measures are presented but the most effective way is to reduce malfunction protection time. Although rotor angle lessening is achieved by integrating TCSC in asymmetrical fault conditions, TCSC 
has no appreciable impact on transient stability during symmetrical 3-phase transmission line faults. In this case installing TCSC into the weak grid is seen as an auxiliary method rather than a fundamental one. In the future, however, a combination of tripping time reduction and integrating TCSC equipments is likely to become the best ultimate solution.

\section{REFERENCES}

[1] Liaoning Electric Power Co., Ltd, State Grid Corporation of China, Report on Liaoning electric grid operation and control in 2013[R]. Liaoning : Liaoning Electric Power Co., Ltd, State Grid Corporation of China, 2012.

[2] Huang Rui, Zhang Bo, Zhang Jicheng. Analysis of reasons for $10 \mathrm{kV}$ substation circuit breaker failure operation [J]. Sichuan electric Power Technology, 2007, 30(6): 28-32.

[3] Yang Zhengqiang. Analysis of reasons for $6 \mathrm{kV}$ switchgear failure operation and solutions[J].Electric Power Safety Technology, 2012,2(14): 34-36.

[4] Ma Fujiang, Zhang Yazhen, Li Fumian, Ma Xiangrong. Analysis and realization of $66 \mathrm{kV}$ malfunction protection scheme $[\mathrm{J}]$. Thermoelectricity Technology, 2005,4: 29-31.
[5] Guo Weiwei, Li Zhao, Song Yanan. Analysis of reasons for $110 \mathrm{kV}$ bus switch rejects to operate [J]. Urban Electrification, 2012,4: 1718.

[6] Cheng Gang, Song Hanrong, Ye Tao, Chen Xi. Analysis of 110kV line mistaken operation and solutions $[\mathrm{J}]$. Water Resources and Power, 2012,11(30): 162-166.

[7] Gao Pijian. Analysis and being on guard to refused action accident of 220kV switch [J]. Industrial Safety and Dust Control, 2000,5: 40-42.

[8] Zhang Jun, Qi Yi. The transaction \& analysis of the representative accident on power network [J]. Ningxia Electric Power, 2004, 4: 18-20.

[9] D P Kothari, I J Nagrath. Power System Engineering (Second Edition) [M]. Beijing : Tsinghua University Express, 2009: 558635.

[10] Electric Power Research Institute, China. Power System Analysis Software Package, User-Defined Model \& User Program Interface User' s Manual (Version6.0) [M]. Beijing : State Grid Express, 2005: 2.1-4.4

[11] Hu Yufeng, Yin Xianggen, Chen Deshu, Zhang Zhe. Research on protection scheme, allocation and realization of Thyristor Controlled Series Compensation (TCSC) [J]. Relay, 2003， 7(31): 28-32.

[12] Wu Shouyuan, Dai Chaobo, Wang Yuhong. Introduction of Thyristor Controlled Series Compensation transmission technology and its recent development $[\mathrm{J}]$. Technology, 2009, 1: 96-100. 